\title{
Research on the influence of the COVID-19 epidemic on work stress of returning workers in China: A study based on empirical analyses of industrial enterprises
}

\author{
Qiang Yang ${ }^{1}$, Jiale Huo ${ }^{1, *}$, Jiang Li $^{1}$ and Yushi Jiang ${ }^{1}$ \\ School of Economics and Management, Southwest Jiaotong University, Chengdu, China
}

Received 7 March 2020

Accepted 15 July 2020

\begin{abstract}
.
BACKGROUND: The COVID-19 epidemic not only cast a shadow on China's economic development but also caused phased panic and anxiety among the Chinese population. At the stage when the spread of the epidemic is not completely controlled, the business activities will surely cause employees to worry and produce a work stress reaction.

OBJECTIVE: This study explores the impact of psychosocial stress caused by the COVID-19 epidemic on the work stress of returned workers. Furthermore, we explore the boundary conditions for reducing work stress from the perspectives of perceived organizational support, perceived social support and epidemic awareness.

METHODS: Data were collected within two weeks after the Chinese government announced the work resumption of industrial enterprises. During this period, 526 returned workers participated in the study.

RESULTS: The results showed that the psychosocial stress caused by the epidemic had a positive impact on work stress. Both perceived organizational support and perceived that social support can alleviate the impact of psychosocial stress on work stress. The moderating effect of epidemic awareness was only established in non-severe epidemic areas.

CONCLUSIONS: In the current period of the spread of the COVID-19 epidemic, the conclusions of this study have a certain theoretical significance and practical value.
\end{abstract}

Keywords: Psychosocial stress, organizational support, social support, epidemic awareness, public health emergencies, COVID-19

\section{Introduction}

The sudden outbreak of COVID-19 caused people around the world, but especially in China, to face great physiological and psychological stress. In the face of such a situation, people generally experience

\footnotetext{
${ }^{1}$ All authors contributed equally to this paper.

*Address for correspondence: Jiale Huo, School of Economics and Management, Southwest Jiaotong University, No. 111, North 1st Section, 2nd Ring Road, Chengdu, 610031, China. E-mail: yq@my.swjtu.edu.cn.
}

a certain degree of psychosocial stress, such as panic and anxiety. To prevent the spread of the epidemic, China has taken strict self-isolation measures and postponed the return to work of enterprises after the Spring Festival holiday [1]. However, China's industrial manufacturing industry is an important part of the global supply chain, and the delayed resumption of industrial production will seriously affect China's economic recovery and even the operation of the global supply chain. The negative impact of the epidemic on China's economy has aroused widespread 
concern around the world. Three weeks after the general self-isolation, the governments all over China issued a return to work schedule to restore economic activity. However, after some enterprises return to work, there are large-scale infection events, which may cause new work stress due to employees' worries about the epidemic situation and psychosocial stress [2] and then reduce the enthusiasm and productivity of employees [3], even spawning slacking and antisocial behavior [4]. On the other hand, a large number of studies have shown that psychosocial stress can have an important impact on the immune system [5]. Psychosocial stress can cause an increase in heart rate, blood pressure and salivary cortisol $[6,7]$. At present, in the absence of specific drugs, improving personal immunity is the main preventive measure ordinary people can take against the novel coronavirus [8]. During the epidemic, ensuring the safety of returning workers is also the focus of the enterprise's work, so timely intervention of the possible work stress of the returning workers is particularly important during this period [9]. It is urgent for Chinese industrial enterprises to return to work, and how to prevent the work stress caused by the epidemic will become the key issue for them to survive and recover in this "epidemic-economic war".

Due to the global lack of experience in dealing with large-scale public health emergencies [10], there is a lack of empirical and theoretical research on the work stress of returning workers in public health emergencies, so theorists and practitioners urgently need to research the impact of psychosocial stress on the work stress of returning workers in public health emergencies and the intervention mechanism. In previous studies, perceived organizational support has been proven to alleviate employees' work stress [11]. Perceived organizational support can improve employees' trust in the organization and improve psychological security. Perceived social support is an external resource available to individuals. It can alleviate the negative effects of stress sources on individuals' physical and mental health $[12,13]$. Individuals' correct cognition of dangerous stressors may help them adjust their self-condition and better deal with stress events. However, in public health emergencies, whether these variables can buffer the relationship between psychosocial stress and work stress needs further verification.

Based on the above reality and theoretical situation, in the special period of the spread of COVID-19 in China and industrial enterprises' return to work, this study explored the influence of psychosocial stress caused by COVID-19 on returning workers' work stress through an online questionnaire survey. Furthermore, this study discussed the boundary conditions of the impact of returning workers' Psychosocial stress on work stress in industrial enterprises. From the perspective of organizational management and social crisis management. We consider the impact of external support (perceived social support) and internal support (perceived organizational support) and epidemic awareness. The study also compared the differences between severe and non-severe epidemic areas. The conclusion of this study has certain theoretical significance and practical value.

\section{Literature review and research hypothesis}

\subsection{The relationship between psychosocial stress and work stress}

Psychosocial stress refers to the phenomenon that occurs when an individual's adaptive response is affected by stressors, leading to internal homeostasis disorder [14]. Social stressors come from events that cause life changes, and these events require individuals to adapt to and cope with life situations and changes [15]. Under the influence of cognition, individual characteristics and other factors, the brain translates these events into abstract ideas and recognizes, processes, and stores them, which can then cause various diseases through neuroendocrine-immune system interactions [5]. Public health emergencies are an important stressor that generates universal psychosocial stress. It has been found that during the outbreak of SARS, Hong Kong influenza and avian influenza [8, 16, 17], the affected local people faced psychosocial stress of adaptive response. The main manifestations are depression, panic and anxiety, and defensive stress responses may be produced [5]. Zhang et al. investigated the mental health status of Wuhan front-line medical staff, and found that nearly one-third of Wuhan front-line medical workers showed higher anxiety than ordinary medical workers [18].

Work stress is a kind of physiological and psychological instinctive response of human beings to work requirements that are beyond their professional ability, and it is mostly manifested in negative reactions, such as work anxiety, work fatigue or burnout and emotional exhaustion [2]. Conservation of resources theory (COR) explains the causes of work stress from 
the two aspects of resource loss and income [19], which holds that people are motivated to conserve existing resources and obtain new resources and tend to seek external resources (such as support from colleagues and leaders) to make up for personal resource loss and effectively cope with future work [20]. According to COR, the psychosocial stress brought by the epidemic is an event involving high resource depletion [10], which consumes a large amount of individual physiological, psychological and cognitive resources [19]. In the stage when epidemic development and crisis events are not effectively controlled, employees returning to work face disease risks and concerns about the economic development of the enterprise. At this time, the loss of resources perceived by returning workers is far higher than the benefit of the resources gained. If the organization fails to respond effectively, a higher level of work stress is formed. Based on this, we hypothesize that the psychosocial stress caused by COVID-19 will cause work stress for returning employees.

Hypothesis 1: The level of psychosocial stress caused by the COVID-19 epidemic will positively affect the level of work stress of returning workers.

\subsection{The moderating role of perceived organizational support}

Perceived organizational support refers to the degree to which an individual perceives that an organization values his/her worth and contribution and cares about his/her benefits [21], including support from colleagues, leaders, organizations, salaries, promotions, etc. Previous studies have shown that in organizational management contexts, perceived organizational support can improve employee organizational trust, and organizational trust can bring better psychological safety [22]. Employees' perception of the organizational atmosphere is affected by organizational support, and the increase in perceived organizational support increases employees' perception of a safe atmosphere [21]. Han, Liu and Chen believe that the psychological safety of employees includes organizational psychological safety and interpersonal psychological safety [23], and the perception of organizational psychological safety comes from organizational support and organizational atmosphere [24, 25]. Therefore, during the COVID-19 epidemic, when returning workers face psychosocial stress, organizational support can meet their social-emotional needs, improve the psychological safety of employees, and reduce the negative impact of stress on work. Moreover, according to the COR, during the COVID-19 epidemic, returning workers lack the resources or support needed to respond to the epidemic, and their perception of the resumption process is an unbalanced social exchange at the expense of self-sacrifice and eventually produces a work stress response. When employees perceive job support from managers, an increase in psychological safety will reduce the impact of psychosocial stress on work stress. Based on this, we propose the following hypothesis:

Hypothesis 2: Perceived organizational support will weaken the positive effect of psychosocial stress on the work stress of returning workers.

\subsection{The moderating role of perceived social support}

Social support is the general or specific support resources that individuals receive from others or social networks [26], mainly from the support of family, friends, colleagues and neighbors, which can help individuals deal with problems and crises in their work and life. It is the focus of social psychology research at this stage. Research shows that social support has a positive impact on individuals' mental health and job performance $[12,13]$. However, perceived lack of social support is negatively correlated with inertia, anxiety, depression and antisocial behavior $[27,28]$. Some researchers believe that social support is confirmed by personal subjective perception and evaluation. Perceived social support can be divided into the availability and appropriateness of social support [29].

In the study of the relationship among perceived social support, stress and mental health, some scholars put forward the buffer model [26], according to which social support improves the physical and mental health of individuals by eliminating individual stress. Perceived social support can buffer the negative impact of stressors on individuals' physical and mental health [30], which acts on the intermediate link between stress sources and individuals' subjective evaluation. If people perceive a high level of social support, they will consider the corresponding stressors less severe and develop improved subjective cognition and self-response ability to reduce the assessment of the degree of harm associated with stress events [31]. Other scholars have proven that 
perceived social support plays a buffer role between psychological stress experience and disease [32]. Social support can provide strategies to solve problems, reduce the uncontrollability of problems, and thus reduce the negative effects of psychological stress. Based on this, we believe that during the period of the COVID-19 epidemic, perceived social support can alleviate the pressure of psychosocial stress, and individuals perceive the acquisition of external resources to make up for the loss of personal resources and then reduce the impact on the work stress response of returning workers. Based on this, we propose the following hypothesis:

Hypothesis 3: Perceived social support will weaken the positive effect of psychosocial stress on the work stress of returning workers.

\subsection{The moderating role of epidemic awareness}

Epidemic awareness refers to the individual's perception of COVID-19 information. From the perspective of psychological processing, both panic and anxiety are based on the individual's cognition of relevant events [33]. Specifically, during the COVID-19 epidemic, individuals first obtain information about the epidemic through multiple channels, such as TV, Internet, and social media, and then establish a cognition of the epidemic based on this information [34], which may or may not be comprehensive. Then, based on their cognition of the epidemic situation, they have a psychological experience of the epidemic situation, that is, a stress response to the epidemic situation. In general, people have negative emotional experiences, such as worry, panic, or anxiety. Then, according to the individual's understanding of the epidemic situation and their emotions at that time, they show a behavioral response consistent with their cognition and emotions. Studies have shown that individuals are prone to cognitive biases during high-stress events [35] and thus form nonadaptive cognition, i.e., incorrect perceptions and outcome expectations of individual responses to stress events $[36,37]$. At present, there is a lot of information related to COVID-19 prevention and control in China. While government departments disclose information on time, rumors are also growing [32]. For returning workers, the main concerns are whether the epidemic information is accurate, whether the epidemic information is timely, etc. In the face of so much information, they do not know which information to believe. If their epidemic awareness deviates

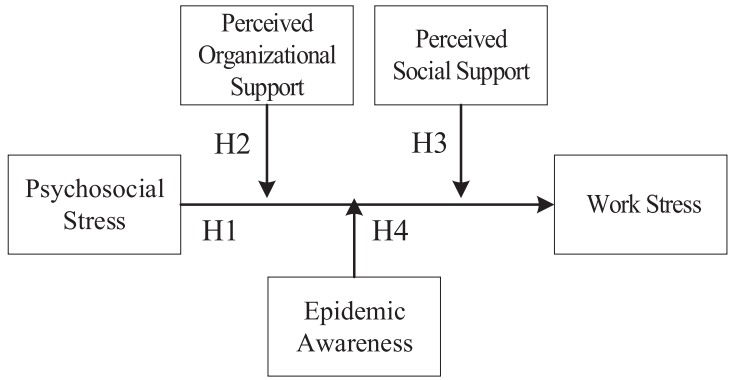

Fig. 1. Conceptual model diagram of this research.

from the actual situation, individuals' panic and psychosocial stress may increase to a certain extent and then affect their work behavior. Therefore, it can be seen that to alleviate the psychosocial stress of the returning workers and prevent them from producing a work stress response, the correct cognition of the employees regarding the epidemic situation is the key influencing factor. Based on this, we propose the following hypothesis:

Hypothesis 4: Epidemic awareness will weaken the positive effect of psychosocial stress on the work stress of returning workers.

According to the above hypothesis deduction, a comprehensive conceptual model of this study is proposed, as shown in Fig. 1. It should be emphasized that during the COVID-19 epidemic, the spread of the epidemic varies across provinces and cities in China, and the government publishes information about the epidemic in a timely manner to the whole country through various media, so the returning workers in different provinces, cities and regions may have different degrees of psychosocial stress. To explore the differences in the work stress and coping mechanisms of returning workers in areas where the epidemic has spread to different degrees.

The impact of epidemic situation on psychosocial stress is personal subjective feeling, which will be affected by external information [8]. After the outbreak of coronavirus, people learned about the epidemic situation mainly through news reports in the media, which will affect people's subjective cognition of the severity of the regional epidemic. Thus we refer to the previous research on SARS $[8,38]$, set the classification standard of the epidemic area in the media news as the standard of this paper. Based on this, we refer to the classification standards of epidemic areas in multiple media. For example, people's daily, China's mainstream media, and a widely 
used platform for epidemic implementation (Ding Xiang Doctor). At the same time, we checked the relevant news of the China Health Commission. In these media platforms, the confirmed cases number 1-9, 10-99, 100-499, 500-1000, >1000 are divided into five levels, and $>1000$ are designated as the severe epidemic areas. Based on this, we regarded provinces and cities with more than 1000 confirmed cases (data as of 12 February 2020) as severe epidemic areas and provinces and cities with fewer than 1000 confirmed cases as non-severe epidemic areas for model validation.

\section{Methods}

\subsection{Data collection}

This study used snowball sampling and entrusted third-party companies to issue questionnaires to returning workers of industrial enterprises from February 12 to February 19 and collected data through the Internet. A total of 542 questionnaires were received. After removing the questionnaires with more than five consecutive extreme values or more than three missing values, 526 valid questionnaires were obtained. The respondents included 287 men $(54.56 \%)$ and 239 women (45.44\%). In terms of age, $25.3 \%$ of the respondents were under 25 years old, $34.0 \%$ between 26 and 30 years old, $19.4 \%$ between 31 and 35 years old, $12.4 \%$ between 36 and 40 years old, and $8.9 \%$ over 41 years of age. In terms of the nature of the enterprise, $43.3 \%$ were state-owned enterprises, $35.6 \%$ were private enterprises, $12.4 \%$ were foreign-funded enterprises, and $8.7 \%$ were other types. In terms of job titles, the general staff accounted for $58.4 \%$, primary management accounted for $30.0 \%$, and middle management accounted for $11.6 \%$. In terms of the educational level of the respondents, $24.5 \%$ had master's degrees and above, $65.2 \%$ were undergraduates, and $10.3 \%$ had junior college education and below. In terms of sample distribution, there were 324 respondents from non-severe epidemic areas, such as Beijing, Jilin, Liaoning, Shanxi, Shaanxi, and Sichuan, and 202 respondents from severe epidemic areas, such as Hubei, Guangdong, Zhejiang, and Henan.

\subsection{Measures}

To verify the rationality of the theoretical model and ensure the reliability and validity of the question- naire measurements, the scales of the five important latent variables in this study were determined on the basis of existing studies, except for epidemic awareness.

\subsubsection{Psychosocial stress}

Referring to Tong's [8] and Shi's [38] method of measurement in the study of the SARS epidemic, this study adopted 12 item-General Health Questionnaire (GHQ-12) and adjusted according to the coronavirus situation to measure psychosocial stress. The scale s widely used after the outbreak of the COVID-19 and has strong credibility. The scale consists of 12 questions and is scored on a 4-point Likert scale ( 1 = "none or almost none" and 4 = "almost always"). The higher the score is, the more severe the psychosocial stress response. Sample items include the following: "During the COVID-19 outbreak, I felt unable to concentrate", "I was losing sleep over the COVID-19 outbreak", "During the COVID-19 outbreak, I often felt powerless". The Cronbach's alpha coefficient of the scale in this study was 0.763 .

\subsubsection{Work stress}

The measurement of work stress was adopted from the scale of Jonge and Schaufeli [39]. The scale included eight items, representing different levels from 1 (strongly disagree) to 5 (strongly agree) and measuring items regarding the stress responses of employees at the physical and psychological levels. Examples include "My job seems to consist of crises" and "I feel tired at work". The Cronbach's alpha coefficient of the scale was 0.875 .

\subsubsection{Perceived organizational support}

This study used the 8-item 5-level Likert scale developed by Rhoades, Eisenberger and Armeli to measure perceived organizational support for demobilized workers [40], representing different levels from 1 (strongly disagree) to 5 (strongly agree). Examples included "When I have problems, my organization can provide help" and "If I need special help, my organization is willing to help me". The Cronbach's alpha coefficient of the scale was 0.793.

\subsubsection{Perceived social support}

This study used the Multidimensional Scale of Perceived Social Support (MSPSS) of Zimet et al. to measure the perceived social support of demobilized workers [41]. MSPSS consists of 3 subscales, which measure the perceived support from family, friends and a significant other. Examples include "I have 
Table 1

Results of confirmatory factor analysis

\begin{tabular}{lcccccc}
\hline Model & $\chi^{2}$ & $d f$ & $\chi^{2} / d f$ & TLI & CFI & RMSEA \\
\hline Five-factor & 315.301 & 127 & 2.483 & 0.946 & 0.951 & 0.054 \\
Four-factor & 351.432 & 128 & 2.746 & 0.863 & 0.895 & 0.076 \\
Three-factor & 563.482 & 131 & 4.301 & 0.826 & 0.856 & 0.075 \\
Two-factor & 730.691 & 133 & 5.494 & 0.781 & 0.823 & 0.082 \\
Single factor & 1352.133 & 134 & 10.091 & 0.671 & 0.721 & 0.093 \\
\hline
\end{tabular}

a special person who can share happiness and sadness with me", "I have a special person around me who always considers how I feel". We used the 5level Likert scale, representing different levels from 1 (strongly disagree) to 5 (strongly agree). As this study focuses on the impact of overall perceived social support on demobilized workers, so the analysis EFA by exploratory factor model to calculate the composite score perceived social support of respondents using factor load factor weighted way. The Cronbach's alpha coefficient of the scale was 0.747 .

\subsubsection{Epidemic awareness}

For the measurement of epidemic awareness. The study used Tong's cognitive measurement scale developed for the SARS epidemic [8]. We used 4 items that can reflect the epidemic awareness. Participants responded to all items on 5-point Likert scales with endpoints of 1 (strongly disagree) to 5 (strongly agree). The measurement items were: "I have a good understanding of the symptoms of COVID-19 infection", "I have a good understanding of the transmission route and mechanism of COVID19", "I have a good understanding of the prevention methods of COVID-19", and "I believe that humans will surely defeat COVID-19". The Cronbach's alpha coefficient of the scale was 0.729 .

\section{Data analyses and results}

\subsection{Confirmatory factor analysis}

We used Mplus 7.0 software for confirmatory factor analysis (CFI) to test the discriminant validity between the main variables. Based on the five-factor model (psychosocial stress, perceived organizational support, perceived social support, epidemic awareness, epidemic awareness considered separately), four competition models were constructed: a four-factor model (perceived organizational support and perceived social support classified as the same latent variable), a three-factor model (three regulatory variables classified as the same latent variable), and a two-factor model (independent variable and adjustment). Section variables were classified as the same (latent variables) and single factor model (correlation coefficient was set to 1). As shown in Table 1, this paper assumes that the five-factor structure of the model has a significantly better fitting effect than other competitive models, and the fitting index is better than the acceptable level $\left(\chi^{2} / d f=2.483, T L I=0.946\right.$, $C F I=0.951, R E S E A=0.054, S R M R=0.057)$, which supports the discriminant validity of the model measured in this paper. In addition, Harman's single factor test showed that the fitting effect of the single factor model was the worst and did not reach the acceptable minimum level $\left(\chi^{2} / d f=\right.$ 10.091, $T L I=0.671, C F I=0.721, R M S E A=0.137$, $S R M R=0.174)$. Therefore, there is no serious common method bias effect in this study.

\subsection{Descriptive statistics and correlation analysis}

By sorting and calculating the questionnaire data, the mean and standard deviation of the relevant variables and the correlation coefficient between the variables are shown in Table 2. There is a significant correlation between the work stress of returning employees and the main research variables, among which there is a significant positive correlation with the level of psychosocial stress $(r=0.543, p<0.01)$, which proves that the epidemic caused personal $p s y$ chosocial stress, which in turn had an impact on the work stress of returning workers in industrial enterprises. Hypothesis H1 in this study is initially verified.

\subsection{Hypothesis test}

We further validated the hypothesis and conducted a hierarchical regression analysis on the relationship between the core variables on the basis of controlling gender, age, position, education and 
Table 2

Descriptive statistics and correlation coefficients for each variable

\begin{tabular}{|c|c|c|c|c|c|c|c|c|c|c|c|}
\hline & Mean & SD & 1 & 2 & 3 & 4 & 5 & 6 & 7 & 8 & 9 \\
\hline 1 Gender & 0.548 & 0.498 & & & & & & & & & \\
\hline 2 Age & 2.456 & 1.241 & $0.082^{* *}$ & & & & & & & & \\
\hline 3 Education & 2.143 & 0.573 & 0.035 & $0.143^{* *}$ & & & & & & & \\
\hline 4 Position & 1.532 & 0.694 & $0.118^{* *}$ & $0.252^{* *}$ & $0.245^{* *}$ & & & & & & \\
\hline 5 Enterprise Nature & 1.872 & 0.953 & $0.232^{* *}$ & 0.032 & 0.024 & 0.034 & & & & & \\
\hline 6 Psychosocial Stress & 15.313 & 3.165 & $0.135^{* *}$ & 0.029 & $0.820^{*}$ & $0.222^{* *}$ & 0.045 & & & & \\
\hline $\begin{array}{l}7 \text { Perceived Organizational } \\
\text { Support }\end{array}$ & 3.486 & 0.887 & 0.048 & $-0.130^{* *}$ & $0.045^{* *}$ & $0.143^{* *}$ & -0.028 & $0.134^{* *}$ & & & \\
\hline 8 Perceived Social Support & 3.457 & 0.835 & $0.065^{*}$ & -0.033 & 0.027 & $0.065^{*}$ & $-0.069^{*}$ & $0.194^{* *}$ & $0.252^{* *}$ & & \\
\hline 9 Epidemic Awareness & 3.343 & 0.764 & 0.032 & $-0.082^{* *}$ & $0.151^{* *}$ & $0.137^{* *}$ & -0.034 & $0.249^{* *}$ & $0.087^{* *}$ & $0.289^{* *}$ & \\
\hline 10 Work Stress & 3.376 & 0.512 & $0.076^{*}$ & $-0.112^{* *}$ & $0.123^{* *}$ & $0.275^{* *}$ & -0.047 & $0.543^{* *}$ & $-0.371^{* *}$ & $-0.462^{* *}$ & $-0.196^{* *}$ \\
\hline
\end{tabular}

Note: $\mathrm{N}=526 ;{ }^{*} p<0.05 ;{ }^{* *} p<0.01 ;{ }^{* * *} p<0.001$, Two-tailed test.

Table 3

Hypothesis test results analysis (severe epidemic areas)

\begin{tabular}{|c|c|c|c|c|c|c|c|c|}
\hline \multirow[t]{2}{*}{ Variable } & \multicolumn{2}{|c|}{ Model 1} & \multicolumn{2}{|c|}{ Model 2} & \multicolumn{2}{|c|}{ Model 3} & \multicolumn{2}{|c|}{ Model 4} \\
\hline & $\beta$ & SE & $\beta$ & SE & $\beta$ & SE & $\beta$ & SE \\
\hline Gender & 0.022 & 0.014 & 0.015 & 0.011 & 0.013 & 0.007 & 0.012 & 0.013 \\
\hline Age & $-0.038^{*}$ & 0.013 & -0.020 & 0.009 & -0.018 & 0.010 & $-0.026^{*}$ & 0.014 \\
\hline Education & $0.056^{*}$ & 0.043 & $0.032^{*}$ & 0.016 & $0.031^{*}$ & 0.011 & $0.026^{*}$ & 0.013 \\
\hline Position & $-0.042^{* *}$ & 0.024 & $-0.031^{*}$ & 0.014 & $0.022^{*}$ & 0.011 & $0.028^{*}$ & 0.016 \\
\hline Enterprise Nature & -0.025 & 0.011 & -0.014 & 0.011 & -0.012 & 0.007 & -0.014 & 0.008 \\
\hline PS & $0.371^{\text {*** }}$ & 0.114 & $0.314^{* * *}$ & 0.075 & $0.284^{* * *}$ & 0.072 & $0.332^{* * *}$ & 0.084 \\
\hline POS & & & $-0.196^{* * *}$ & 0.032 & & & & \\
\hline $\mathrm{PS} * \mathrm{POS}$ & & & $-0.153^{* * *}$ & 0.035 & & & & \\
\hline PSS & & & & & $-0.143^{* *}$ & 0.068 & & \\
\hline PS * PSS & & & & & $-0.176^{* * *}$ & 0.038 & & \\
\hline EA & & & & & & & -0.074 & 0.043 \\
\hline PS * EA & & & & & & & -0.043 & 0.032 \\
\hline $\mathrm{R}^{2}$ & 0.362 & & 0.393 & & 0.391 & & 0.374 & \\
\hline$\Delta R^{2}$ & 0.362 & & 0.031 & & 0.029 & & 0.012 & \\
\hline $\mathrm{F}$ & $4.621^{* *}$ & & $5.113^{* *}$ & & $4.872^{* *}$ & & $4.648^{* *}$ & \\
\hline DW & 1.843 & & 1.882 & & 1.757 & & 1.835 & \\
\hline
\end{tabular}

Note: $\mathrm{N}=202 ;{ }^{*} p<0.05 ;{ }^{* *} p<0.01 ;{ }^{* * *} p<0.001$, Two-tailed test; PS = Psychosocial Stress; POS = Perceived Organizational Support; PSS $=$ Perceived Social Support EA = Epidemic Awareness.

the nature of the enterprise. To explore the differences between the severe and non-severe epidemic areas, the regression models of these two sample data were constructed, and the results are shown in Tables 3 and 4. In the model construction, the interaction term data are centralized to avoid multiple collinearity, and the potential effects of multiple collinearity and residual autocorrelation are evaluated using VIF values and DW statistics, respectively. The test results show that the VIF is between $1-5$, which can basically reject the possibility of multiple collinearity between variables; the DW value is between 1.7-2, which indicates that there is no autocorrelation between residual terms. Moreover, Tables 3 and 4 show that the $\mathrm{R}^{2}$ of each model exceeds 0.362 at the lowest level, and the F value is significant, which indicates that the constructed model is reasonable.

\subsubsection{The main effect test of psychosocial stress}

Model 1 and Model 5 examined the main effect of individual psychosocial stress caused by the COVID-19 epidemic on the work stress response of returning workers. The results showed that psychosocial stress had a significant positive effect on employees' work stress whether in the severe epidemic areas or in the non-severe epidemic areas (severe epidemic areas: $\beta=0.371, p<0.001$; nonsevere epidemic areas: $\beta=0.335, p<0.001$ ), so the hypothesis of H1 was confirmed. Further comparison of the stress difference between the severe and non-severe epidemic areas showed that the respondents in the severely affected areas had higher levels of psychosocial stress $\left(\mathrm{M}_{\text {non-severeareas }}=13.62\right.$; $\mathrm{M}_{\text {severeareas }}=15.83$ ) and higher work stress (higher $\beta)$. This indicates that the workers in the severely affected areas face greater work stress. 
Table 4

Hypothesis test results analysis (non-severe epidemic areas)

\begin{tabular}{|c|c|c|c|c|c|c|c|c|}
\hline \multirow[t]{2}{*}{ Variable } & \multicolumn{2}{|c|}{ Model $5(\mathrm{H} 1)$} & \multicolumn{2}{|c|}{ Model $6(\mathrm{H} 2)$} & \multicolumn{2}{|c|}{ Model 7 (H3) } & \multicolumn{2}{|c|}{ Model $8(\mathrm{H} 4)$} \\
\hline & $\beta$ & SE & $\beta$ & SE & $\beta$ & SE & $\beta$ & SE. \\
\hline Gender & $0.042^{*}$ & 0.023 & $0.044^{*}$ & 0.012 & 0.024 & 0.013 & 0.022 & 0.014 \\
\hline Age & 0.021 & 0.013 & -0.014 & 0.012 & -0.013 & 0.008 & -0.012 & 0.007 \\
\hline Education & $0.063^{*}$ & 0.024 & $0.054^{*}$ & 0.021 & $0.043^{*}$ & 0.032 & $0.061^{*}$ & 0.014 \\
\hline Position & $0.069^{*}$ & 0.033 & $0.052^{*}$ & 0.022 & $0.051^{*}$ & 0.012 & $0.033^{*}$ & 0.015 \\
\hline Enterprise Nature & 0.026 & 0.013 & 0.013 & 0.012 & -0.011 & 0.007 & 0.012 & 0.006 \\
\hline PS & $0.335^{* * *}$ & 0.104 & $0.255^{* * *}$ & 0.112 & $0.237^{* * *}$ & 0.063 & $0.226^{* * *}$ & 0.042 \\
\hline POS & & & $-0.175^{* * *}$ & 0.104 & & & & \\
\hline PS * POS & & & $-0.148^{* * *}$ & 0.072 & & & & \\
\hline PSS & & & & & $-0.145^{* * *}$ & 0.049 & & \\
\hline $\mathrm{PS} * \mathrm{PSS}$ & & & & & $-0.131^{* *}$ & 0.065 & & \\
\hline EA & & & & & & & $-0.139^{* * *}$ & 0.083 \\
\hline $\mathrm{PS} * \mathrm{EA}$ & & & & & & & $-0.143^{* * *}$ & 0.047 \\
\hline $\mathrm{R}^{2}$ & 0.366 & & 0.399 & & 0.392 & & 0.390 & \\
\hline$\Delta \mathrm{R}^{2}$ & 0.366 & & 0.033 & & 0.026 & & 0.024 & \\
\hline $\mathrm{F}$ & $5.154^{* *}$ & & $5.279^{* *}$ & & $4.693^{* *}$ & & $5.169^{* *}$ & \\
\hline DW & 1.843 & & 1.827 & & 1.817 & & 1.832 & \\
\hline
\end{tabular}

Note: $\mathrm{N}=324 ;{ }^{*} p<0.05 ;{ }^{* *} p<0.01 ;{ }^{* * *} p<0.001$, Two-tailed test; PS = Psychosocial Stress; POS = Perceived Organizational Support; PSS $=$ Perceived Social Support EA $=$ Epidemic Awareness .

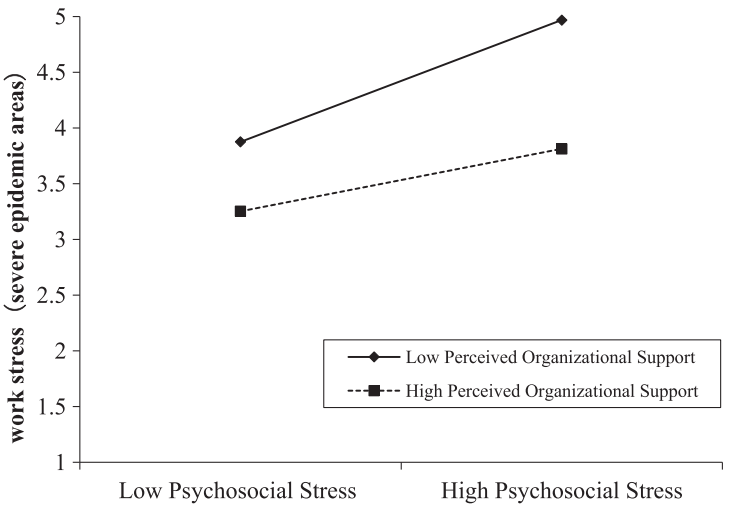

Fig. 2. Moderating effect of perceived organizational support between psychosocial stress and work stress in severe epidemic areas.

\subsubsection{The moderating role of perceived organizational support}

Model 2 and Model 6 examined the moderating effect of perceived organizational support on psychosocial stress and work stress. The overall explanatory power of Model 2 and Model 6 was incremental (severe epidemic areas Model 2: $\Delta \mathrm{R}^{2}=0.031, p<0.01$; non-severe epidemic areas Model 6: $\Delta \mathrm{R}^{2}=0.033, p<0.01$ ), and the interaction terms of perceived organizational support and psychosocial stress were significant in different epidemic areas (severe epidemic areas: $\beta=-0.153, p<0.001$; non-severe epidemic areas: $\beta=-0.148, p<0.001$ ). To illustrate the moderating effects of perceived organizational support between psychosocial stress and

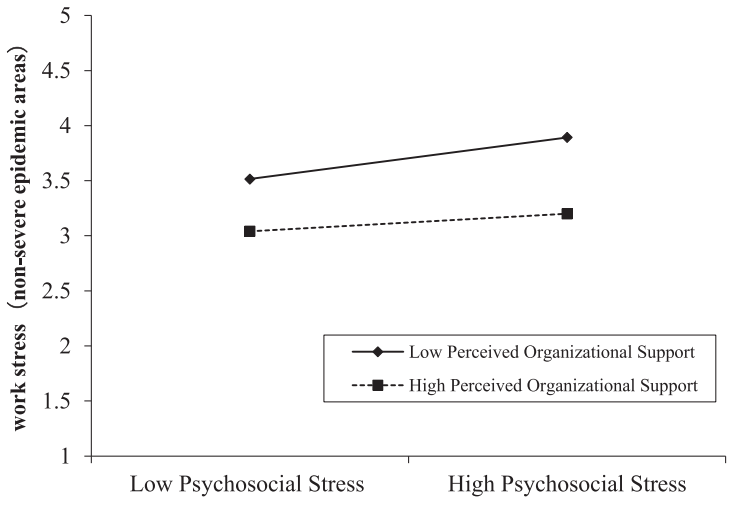

Fig. 3. Moderating effect of perceived organizational support between psychosocial stress and work stress in non-severe epidemic areas.

work stress, refer the analysis process of Peng et al. [42] we plotted the regression of psychosocial stress on work stress in different epidemic areas at high and low levels of perceived organizational support (high, above the median; low, below the median; see Figs. 2 and 3). Results indicate that in the low perceived organizational support, the relationship between $p s y$ chosocial stress and work stress was significant whether in severe epidemic areas $(\beta=0.331, p<0.01)$ or non-severe epidemic areas $(\beta=0.249, p<0.05)$. However, in the high psychological capital group, the association between psychosocial stress and work stress was not significant whether in severe epidemic areas $(\beta=0.161, p=0.515)$ or non-severe epidemic areas $(\beta=0.107, p=0.665)$. It was demonstrated 
that the perceived organizational support of returning employees attenuated the effect of psychosocial stress on work stress, so the hypothesis of $\mathrm{H} 2$ was verified.

\subsubsection{The moderating role of perceived social support}

Model 3 and Model 7 examined the moderating effect of perceived social support on psychosocial stress and work stress in areas with different epidemic severity. On the basis of Model 1 and Model 5, adjusting variables and interaction terms were added, and the overall explanatory power of Model 3 and Model 7 in characterizing the severely affected areas of the epidemic increased by $2.9 \%$ and $2.6 \%$, respectively. In addition, the interaction terms of perceived social support and psychosocial stress had significant effects (severe epidemic areas: $\beta=-0.176, p<0.001$; non-severe epidemic areas: $\beta=-0.131, p<0.001$, indicating that perceived social support regulates the relationship between psychosocial stress and work stress. That is, the higher social support employees perceive, the weaker the impact of the psychosocial stress caused by the epidemic on work stress. This relationship is established in both the severely affected and non-severely affected areas, so hypothesis $\mathrm{H} 3$ is verified.

We plotted the regression of psychosocial stress on work stress in different epidemic areas at high and low levels of perceived social support (high, above the median; low, below the median; see Figs. 4 and 5). Results indicate that in the low perceived social support, psychosocial stress significantly predicted work stress whether in severe epidemic areas $(\beta=0.292$, $p<0.05)$ or non-severe epidemic areas $(\beta=0.177$, $p<0.05$ ). But in the high perceived social support, the relationship between psychosocial stress and work stress was not significant whether in severe epidemic areas $(\beta=0.108, p=0.607)$ or non-severe epidemic areas $(\beta=-0.093, p=0.659)$.

\subsubsection{The moderating role of epidemic awareness}

Model 4 and Model 8 examined the moderating effect of epidemic awareness on psychosocial stress and work stress. Adjustment variables and interaction terms were added to Models 1 and 5, and the overall explanatory power of Model 4, which characterizes the severely affected areas of the epidemic, increased by $1.2 \%, P<0.01$. However, the interaction term between epidemic awareness and psychosocial stress was not significant $(\beta=-0.043, p>0.05)$,

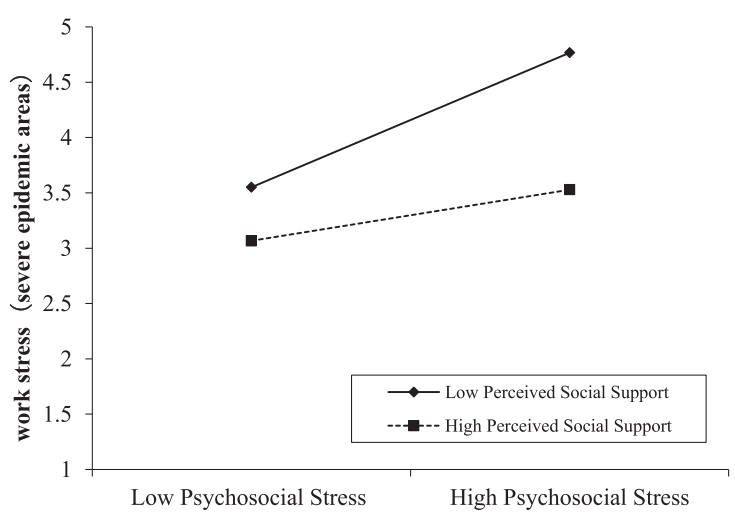

Fig. 4. Moderating effect of perceived social support between psychosocial stress and work stress in severe epidemic areas.

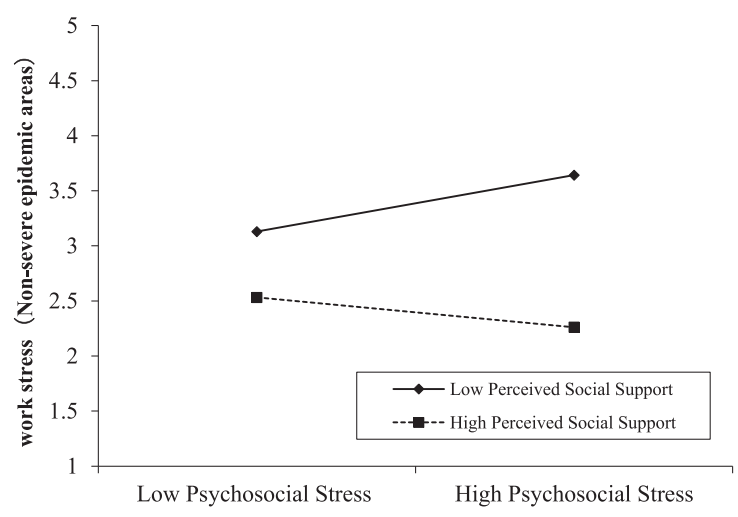

Fig. 5. Moderating effect of perceived social support between psychosocial stress and work stress in non-severe epidemic areas.

indicating that in the severe epidemic areas, the individual's level of epidemic awareness did not play a regulatory role in the relationship between psychosocial stress and work stress. In non-severe epidemic areas, the overall explanatory power of Model 8 was of incremental significance $\left(\Delta \mathrm{R}^{2}=0.024, p<0.01\right)$, and the interaction term between epidemic awareness and psychosocial stress had a significant impact $(\beta=-0.143, p<0.001)$, indicating that in non-severe epidemic areas, the individual's cognitive level of epidemic can attenuate the impact of psychosocial stress on work stress. Therefore, it is assumed that $\mathrm{H} 4$ is only validated in non-severe epidemic areas.

We plotted the regression of psychosocial stress on work stress in different epidemic areas at high and low levels of epidemic awareness (high, above the median; low, below the median; see Figs. 6 and 7). Results indicate that in severe epidemic areas, the relationship between psychosocial stress and work stress was not significant whether in the low 


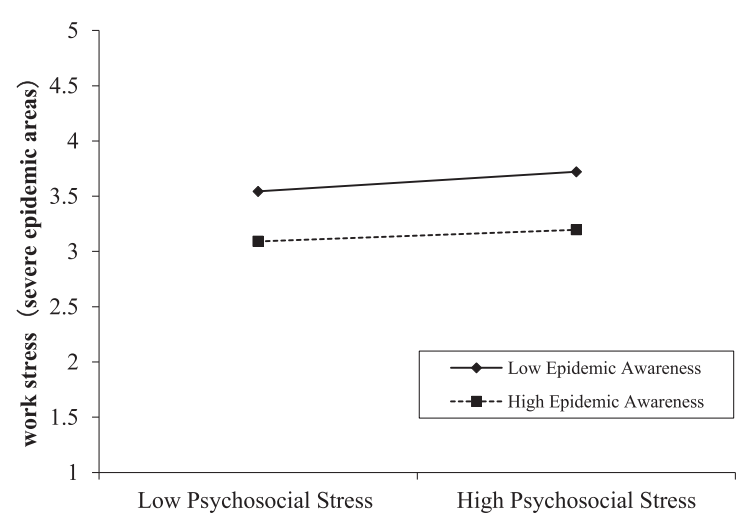

Fig. 6. Moderating effect of epidemic awareness between psychosocial stress and work stress in severe epidemic areas.

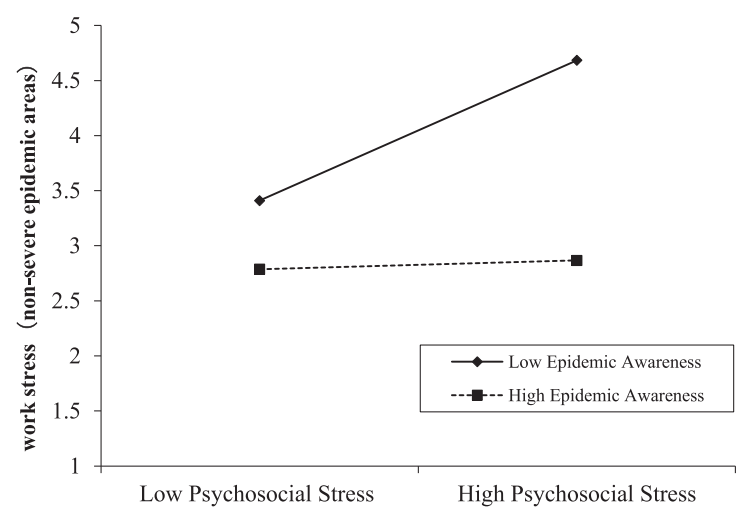

Fig. 7. Moderating effect of epidemic awareness between psychosocial stress and work stress in non-severe epidemic areas.

epidemic awareness $(\beta=0.201, p=0.668)$ or high epidemic awareness $(\beta=0.120, p=0.863)$. However, in non-severe epidemic areas, psychosocial stress significantly predicted work stress when epidemic awareness is low $(\beta=0.366, p<0.01)$. and the relationship between psychosocial stress and work stress was not significant when the epidemic awareness is high $(\beta=0.023, p=0.725)$.

\section{Discussion}

Since 2020, COVID-19 has been raging in most countries around the world, which has brought widespread psychosocial stress. To control the pandemic, many governments have taken measures to stop work and home isolation. Nowadays, the global workers must return to work, but at this stage, some enterprises have large-scale infection events, which may cause new work stress [2], and then reduce their work enthusiasm and productivity [3], there was even sabotage and antisocial behavior [17]. Due to the sudden and accidental nature of the pandemic in history, there are a few studies on the impact of social-psychological stress caused by public health events on the work stress of returning workers. To make up for the related theoretical defects, this study survey the returning workers in Chinese industrial enterprises and discussed the impact of individual psychosocial stress on work stress in different epidemic disaster areas and explored the moderating effect of perceived organizational support, perceived social support and epidemic awareness.

Consistent with previous studies, we found that psychosocial stress has significant effect on the work stress [43]. Similar to other acute psychosocial stress, the psychosocial stress caused by the COVID-19 epidemic promotes the occurrence of work stress. Employees returning to work in the stage when crisis events are not effectively controlled face the risk of infection. Workers in severe epidemic areas have higher psychosocial stress and higher work stress than workers in less severe epidemic areas. Faced with the demobilized workers' concerns about life safety and economic income, enterprises and society should provide more external resources (psychological and physiological) for crisis intervention to alleviate the sense of resource loss.

The study also supports the moderating effects of perceived organizational support and perceived social support in the relationship between psychosocial stress and work stress as suggested in Hypothesis 2 and Hypothesis 3. Our findings corroborate previous research suggesting that people's perceived organizational support and perceived social support alleviate people's work stress $[23,30]$. The theoretical contributions and innovations of this study explored the interaction between perceived organizational support \& perceived social support and psychosocial stress. In different epidemic disaster areas, returning workers' perceived organizational support alleviates the impact of psychosocial stress on work stress. Han et al. indicated that the improvement of perceived organizational support will lead to the improvement of employees' perception of a safe atmosphere [23]. According to the conservation of resources theory, when employees perceive job support from managers, an increase in psychological safety will reduce the impact of psychosocial stress on work stress. On the other hand, perceived social support also weakened the impact of psychosocial stress on work stress. According to the buffer model [26], it can be 
inferred that, when individuals perceive high social support, they will perceive stress problems to be more controllable and the negative effects caused by the psychological and social pressure caused by COVID19 to be less severe by improving their subjective cognition and self-coping ability.

Additionally, epidemic awareness was found has significantly moderate effects between the psychosocial stress and work stress, people's stress response to the COVID-19 depends on their knowledge of the epidemic. If the employee's epidemic awareness is deviated, this may increase the individual's panic and psychological stress to a certain extent [32], which in turn affects his/her work behavior. At the same time, a correct understanding of the epidemic situation will reduce the negative impact of psychological stress on work stress. But in the current study, the mitigation effect differs across epidemic disaster areas. In nonsevere epidemic areas, the higher and more accurate employees' awareness of the epidemic is, the weaker the impact of psychosocial stress on work stress. However, in severe epidemic areas, the regulatory role of epidemic awareness is ineffective. This paper argues that there are two possible reasons for this phenomenon. First, people's psychosocial stress level is generally higher in severe epidemic areas (mean $16.4 \%$ higher than in non-severe epidemic areas), resulting in greater panic and anxiety. Unlike the usual depressive and anxiety disorders, the COVID19 stress response is a specific and acute response. Returning workers sense the aggravation and slower recovery of the epidemic situation in the areas where the epidemic is less severe every day through news reports, which promotes their immediate anxiety and leads them to have greater concerns about their safety, so the regulatory role of epidemic awareness no longer exists. Second, in the current study, the sample data from the non-severe epidemic areas is limited, and there was no significant difference in the respondents' cognitive-level scores about the epidemic, so this aspect could not fully reflect the impact of epidemic awareness on the work stress of the returning workers in the non-severe epidemic areas.

\subsection{Implications}

Theoretically, on the one hand, this study explored the influence of psychosocial stress caused by public health emergencies on work stress of returning workers. In previous studies on the impact of public health emergencies, most of them investigate public governance [44], public opinion monitoring [45] and mental health [46], but few studies concentrate on the work stress response of ordinary employees (not medical staff) after the public health emergencies. Therefore, this study explores the possible impact of public health emergencies on the work stress of enterprise employees, which supplements ed the insufficient research in relevant fields. On the other hand, this study enriches the theoretical research in the field of work stress and expands the theoretical explanation of work stress intervention. this study considered the regulatory role of perceived organizational support, perceived social support and epidemic awareness, explored the extent of the impact of special stressors on work stress.

Practically, the conclusion of this study has certain guiding significance for industrial enterprises operating in China to formulate a stress intervention mechanism for returning workers in response to COVID-19. First, we found that psychosocial stress on the returning workers will further promote the work stress. Industrial enterprises should pay attention to the impact of psychosocial stress brought by the epidemic on the work stress of employees. Especially in Guangdong, Henan and Zhejiang, which are not only the hardest hit areas of the epidemic but also the most important provinces of industrial production in China, employees are very worried about returning to work and face great psychological pressure. Enterprises should regularly evaluate the level of work stress and take measures to prevent such stress. Second, this study found that organizational support and social support are the key factors that alleviate the impact of the epidemic on work stress. Therefore, during the epidemic period, enterprises should provide various material and spiritual support for employees to cope with social and psychological stress and work stress, such as providing more necessities (masks, goggles and other epidemic response necessities) for employees to work, improving disinfection measures in the workplace, demonstrating increased concern of managers for returning workers, creating a safe environment and organizational atmosphere for employees to return to work, and improving psychological safety. Employees with high stress levels should be given timely psychological and medical intervention. Moreover, enterprises should pay attention to employees' perceived social support, pay attention to employees' family interpersonal relationships during the epidemic, and reduce potential work-family conflict. Third, enterprises should pay attention to the epidemic awareness of returning workers. Although the regulatory effect 
of epidemic awareness on the relationship between psychosocial stress and work stress has not been confirmed in severe epidemic areas, the data show that epidemic awareness can also negatively affect the level of work stress. Therefore, enterprises should guide returning workers to pay attention to authoritative information release channels and obtain the latest, most accurate and scientific epidemic information. To counteract rumors and false information that may cause returning workers in the region to misunderstand the epidemic situation, employees should be informed in time to alleviate their worries and panic caused by information confusion.

\subsection{Limitations and future research}

Although this paper focuses on the impact of psychosocial stress caused by COVID-19 on the work stress of industrial workers and the intervention mechanism, there are still some limitations regarding time and resource factors. First, considering the convenience of the study and China's current strict residential segregation policy, this study adopts snowball sampling and entrusts a third-party survey company to conduct network random sampling of relevant groups to collect data. The sample size can only represent a part of the group. More samples should be used in future research to improve the universality of the model. Second, because this study focuses on the impact of overall perceived social support on demobilized workers, there is no separate discussion of the three dimensions of perceived social support (from family, friends and a significant other). Future research can explore this issue in order to discover which social support is most effective in alleviating the psychosocial stress caused by the epidemic. Third, from a micro point of view, this study explores the effects of perceived organizational support, perceived social support and epidemic awareness on work stress. In follow-up studies, we can also explore other predictors (e.g., motivation to return to work) and intervening factors (e.g., government trust) that affect the work stress of the returning workers and introduce more variables into the model to further explore the issue and improve interventions to reduce the work stress of industrial workers during the epidemic.

\section{Conclusion}

In this study, we found that the level of psychosocial stress caused by the COVID-19 epidemic will positively affect the level of work stress of returning workers. perceived organizational support, perceived social support and epidemic awareness appeared to significantly moderate the effect of psychosocial stress on work stress.

\section{Conflict of interest}

None to report.

\section{References}

[1] Xinhua News Agency. Li Keqiang presided over the convening of the Central Leading Group Meeting on New Coronavirus-Infected Pneumonia to further deploy the epidemic prevention and control efforts to improve the recovery and cure rate. Chinese Journal of Integrated Traditional Chinese and Western Medicine. 2020; Available from: http://kns.cnki.net/kcms/detail/11.2787.R.20200207.1628. 002.html

[2] Jones MK, Latreille PL, Sloane PJ. Job Anxiety, Work-Related Psychological Illness and Workplace Performance. British Journal of Industrial Relations. 2015;54(4): 742-67.

[3] Petkovic AI, Nikolic V. Educational needs of employees in work-related stress management. Work. 2020;65(3):661-9.

[4] Mokarami H, Toderi S. Reclassification of the work-related stress questionnaires scales based on the work system model: A scoping review and qualitative study. Work. 2019;64(4):787-95.

[5] Cui RR. Immune Response Rules and Mechanisms of Psychosocial Stress. Progress in Psychological Science. 2019;27(5):821-33.

[6] Al' Absi M, Wittmers LE, Erickson J, Hatsukami D, Crouse B. Attenuated adrenocortical and blood pressure responses to psychological stress in ad libitum and abstinent smokers. Pharmacology Biochemistry and Behavior. 2003;74(2):401-10.

[7] Schoofs D, Preuß D, Wolf OT. Psychosocial stress induces working memory impairments in an n-back paradigm. Psychoneuroendocrinology. 2008;33(5):643-53.

[8] Tong HJ. Model of SARS Stress and It's Character. Acta Psychologica Sinica. 2004;36(1):103-9.

[9] Hassard J, Teoh KR, Visockaite G, Dewe P, Cox T. The Cost of Work-Related Stress to Society: A Systematic Review. Journal of Occupational Health Psychology. 2019;7(116):208-21.

[10] Jacobs J, Oosterbeek M, Tummers LG, Noordegraaf M, Yzermans CJ, Dückers MLA. The organization of post-disaster psychosocial support in the Netherlands: a meta-synthesis. European Journal of Psychotraumatology. 2019;10(1):1544024.

[11] Zeytinoglu IU, Denton M, Brookman C, Davies S, Sayin FK. Health and safety matters! Associations between organizational practices and personal support workers' life and work stress in Ontario, Canada. BMC Health Services Research. 2017;17(1):427.

[12] Cullen FT. Social support as an organizing concept for criminology: Presidential address to the academy of criminal justice sciences. Justice Quarterly. 1994;11(4):527-59. 
[13] Havermans BM, Boot CRL, Houtman ILD, Brouwers EPM, Anema JR, Beek AJ. The role of autonomy and social support in the relation between psychosocial safety climate and stress in health care workers. BMC Public Health. 2017;17(1).

[14] Armstrong LE, VanHeest JL. The Unknown Mechanism of the Overtraining Syndrome. Sports Medicine. 2002;32(3):185-209.

[15] Azzinnari D, Sigrist H, Staehli S, Palme R, Hildebrandt T, Leparc G, Pryce CR. Mouse social stress induces increased fear conditioning, helplessness and fatigue to physical challenge together with markers of altered immune and dopamine function. Neuropharmacology. 2014;85:328-41.

[16] Wong SYS, Wong CK, Chan FWK, Chan PKS, Ngai K, Mercer S, Woo J. Chronic psychosocial stress: does it modulate immunity to the influenza vaccine in Hong Kong Chinese elderly caregivers? Age. 2012;35(4):1479-93.

[17] Sun SJ, Fu H, Wang F. Health Risk Dissemination and Evaluation in H7N9 Avian Influenza Crisis - Based on Empirical Data from Shanghai. Journalist. 2013;(05):55-9.

[18] Zhang Y, Zhang X, Peng JX, Fang P. Mental health survey of medical staff of Wuhan Anti-New Coronary Pneumonia [J]. Journal of Tropical Medicine. 2020:1-7.

[19] Liu L, Mei Q, Wu JN. Employee Well-being, Work stress and Innovative Behavior: The Regulatory Role of Perceived Organizational Support. Science \& Technology Progress and Policy. 2020; Available from: http://kns.cnki.net/ kcms/detail/42.1224.G3. 20191216. 0908.014.html

[20] Hobfoll SE. Conservation of resources: A new attempt at conceptualizing stress. American Psychologist. 1989;44(3): 513-24.

[21] Eisenberger R, Stinglhamber F. Perceived organizational support. Journal of Applied Psychology. 1986;71(3):500-7.

[22] Li N, Yan J. Pathways of organizational trust atmosphere on task performance. Journal of Psychology. 2007;39(6): 1111-21.

[23] Han P, Liu XT, Chen X. An Exploration into the Relationship among Organizational Trust, Psychological Safety and Work stress. Management Review. 2017;29(10):108-19.

[24] Edmondson A. Psychology Safety and Learning Behavior in Teams. Administrative Science Quarterly. 1999;44(2): 350-83.

[25] Kahn WA. Psychological Conditions of Personal Engagement and Disengagement at Work. Academy of Management Journal.1990;33(4):692-724.

[26] Turner RJ, Grindstaff CF, Phillips N. Social Support and Outcome in Teenage Pregnancy. Journal of Health and Social Behavior. 1990;31(1):43.

[27] Jones-Johnson G, Johnson WR. Subjective Underemployment and Psychosocial Stress: The Role of Perceived Social and Supervisor Support. The Journal of Social Psychology. 1992;132(1):11-21.

[28] Gaffey AE, Aranda F, Burns JW, Purim-Shem-Tov YA, Burgess HJ, Beckham JC, Hobfoll SE. Race, psychosocial vulnerability and social support differences in inner-city women's symptoms of posttraumatic stress disorder. Anxiety, Stress, \& Coping. 2018;1-14.

[29] Malecki CK, Demaray MK. Measuring perceived social support, development of the child and adolescents social support scales. Psychology in the School. 2002;39:1-18.

[30] Weinberg M. The Mediating Role of Posttraumatic Stress Disorder with Tendency to Forgive, Social Support, and Psychosocial Functioning of Terror Survivors. Health \& Social Work. 2018;43(3):147-54.
[31] Wang YF. Review on the relationship between social support and physical and mental health. Psychological Science. 2004;(05):1175-7.

[32] Wang WC, Wu XC. The influence of empathy on the prosocial behavior of post-disaster adolescents: the mediating role of gratitude, social support and post-traumatic growth. Psychological Journal. 2020; Publish online. http://kns.cnki. net/kcms/detail/11.1911.B. 20200117.0925.014.html

[33] Gu C, Zhang YL, Liu XL, He YQ. Research on the influence mechanism of self-regulation strategy on entrepreneurial decision-making based on cognitive perspective. Prediction. 2019;38(04):46-53

[34] Yang HB. Scientific Cognition to Alleviate Concern and Panic. Tianjin Daily. [updated 2020 February 19; cited 2020 February 25]. Available from: http://epaper.tianjinwe.com/ tjrb/html/2020-02/19/content_158_2323346.htm

[35] Yi J, Yang Q, Ye BJ. Effects of stress on adolescent problem network use: a chain mediating role of basic psychological needs and non-adaptive cognition. Chinese Journal of Clinical Psychology. 2016;24(04):644-7.

[36] Mai Y, Hu J, Yan Z, Zhen S, Wang S, Zhang W. Structure and function of maladaptive cognitions in Pathological Internet Use among Chinese adolescents. Computers in Human Behavior. 2012;28(6):2376-86.

[37] LaRose R, Eastin MS. A Social Cognitive Theory of Internet Uses and Gratifications: Toward a New Model of Media Attendance. Journal of Broadcasting \& Electronic Media. 2004;48(3):358-77.

[38] Shi K, Fan H, Jia J. The Risk Perceptions of Sars and Socio-Psychological Behaviors of Urban People in China. Psychological Journal. 2003;35(4):546-54.

[39] Jonge J, Schaufeli WB. Job Characteristics and Employee Well-Being: A Test of Warr's Vitamin Model in Health Care Workers Using Structural Equation Modelling. Journal of Organizational Behavior. 1998;19(4):387-407.

[40] Rhoades L, Eisenberger R, Armeli S. Affective commitment to the organization: The contribution of perceived organizational support. Journal of Applied Psychology. 2001;86(5):825-36.

[41] Zimet GD, Dahlem NW, Zimet SG, Farley GK. The Multidimensional Scale of Perceived Social Support. Journal of Personality Assessment. 1988;52(1):30-41.

[42] Peng J, He Y, Deng J, Zheng L, Chang Y, Liu X. Emotional labor strategies and job burnout in preschool teachers: psychological capital as a mediator and moderator. Work. 2019;63(3):335-45.

[43] Lee K, Suh C, Kim J, Park JO. The impact of long working hours on psychosocial stress response among white-collar workers. Industrial Health. 2017;55(1):46-53.

[44] Li YL, Wang J. Research on the Restoration of Social Trust in Public Crisis Management - Taking Public Health Events of Major Animal Epidemics as an Example. Managing the World. 2015;(09):172-3.

[45] Li YL, Ding Y. Research on Restoration of Social Trust in Public Crisis Governance of Internet Public Opinion - Empirical Analysis Based on Evolutionary Game of Animal Epidemic Crisis. Journal of Public Management. 2017;14(04):91-101+157.

[46] Zoupanou Z, Rydstedt LW. The mediating and moderating role of affective rumination between work interruptions and well-being. Work. 2019;62(04):53-61. 